\title{
Material Didático para o Ensino do Italiano a Brasileiros sob o Ponto de Vista da Comunicação Intercultural
}

\author{
Paola Baccin* \\ Faculdade de Filosofia, Letras e Ciências Humanas da Universidade de São Paulo
}

* Autor para correspondência: pbaccin@usp.br

\section{RESUMO}

O material didático para o ensino de línguas estrangeiras produzido pelas grandes editoras internacionais não contempla aspectos linguísticos e, principalmente, culturais dos alunos que estão inseridos em um contexto estrangeiro de aprendizagem. $\mathrm{O}$ aluno brasileiro que aprende italiano no Brasil é beneficiado quando pode entrar em contato com os aspectos linguísticos e sobretudo com aqueles relativos à comunicação intercultural apresentados em um material didático especificamente desenhado para as suas necessidades. O ensino e a aprendizagem assumem, desse modo, uma significação mais concreta.

Palavras-chave: Material Didático; Língua Italiana; Comunicação Intercultural; Material On-line.

\begin{abstract}
The educational materials for the teaching of foreign languages produced by major international publishers does not consider language skills and mainly cultural needs of students in a foreign learning context. We believe that the contact with the linguistic aspects, especially with the aspects of intercultural communication presented in a courseware specifically designed for their needs benefits the Brazilian student. The teaching and learning take thus a more concrete meaning.
\end{abstract}

Keywords: Courseware; Italian Language; Intercultural Communication; Online Material.

\section{Introdução}

O Programa de Pós-Graduação em Língua, Literatura e Cultura Italianas (FFLCH-USP) desenvolveu, em parceria com o Departamento de Mídias Digitais da USP, um conjunto de materiais didáticos que está sendo utilizado em cursos de graduação em língua italiana na Universidade de São Paulo, na Universidade Federal da Bahia, na Universidade Federal do Ceará e será usado pelo Projeto Idiomas sem Fronteiras nas quatro universidades federais que iniciarão, em 2016, o ensino da língua italiana.

Conforme dados de novembro de 2016, o material conta com mais de 3,7 milhões de acessos no portal e-Aulas USP e com mais de trinta mil seguidores em sua página do Facebook.

Neste artigo abordaremos as reflexões e as escolhas didáticas que nos levaram a elaborar esse material didático, o qual apresenta, sobretudo, os elementos linguísticos e culturais que oferecem maior dificuldade ao aluno brasileiro e que, geralmente, não são tratados nos manuais didáticos tradicionais.

Nossa escolha recai sobre a observação de que o aluno brasileiro que estuda a língua italiana conta com material didático produzido por grandes editoras que miram atingir, contemporaneamente, públicos das mais diversas línguas maternas, e, de acordo com o interesse editorial de um determinado momento histórico, são produzidos materiais que visam ao aluno de uma determinada língua. Em geral, esses materiais, realizados sob a óptica do professor que tem o italiano como língua materna, não levam em conta as especificidades do público brasileiro e apresentam uma seleção de textos e exercícios de acordo com uma gradação de dificuldades que nem sempre corresponde às sentidas pelo aluno brasileiro. Citamos como exemplo os verbos 
esserci (haver, existir) e avere (ter), cuja diferença é clara em muitas línguas como, por exemplo, para o inglês, para o francês, para o espanhol, para o alemão. Para o aluno brasileiro, no entanto, essa diferença precisa ser explicitada e praticada por meio de exercícios, precisa ser apresentada mais vezes em textos e situações de usos.

A escolha do material e do conteúdo a ser tratado depende, também, do contexto de aprendizagem. Há dois contextos de aprendizagem de língua estrangeira: alunos que aprendem o italiano na Itália (em host language environment, L2) e aqueles que aprendem a língua estrangeira no seu país de origem (LE).

No primeiro caso, o interesse comunicativo e a comunicação intercultural ocorrem imediata e naturalmente pela imersão do aluno no ambiente da língua estrangeira. $\mathrm{O}$ aluno é convidado ou até mesmo impelido a utilizar a língua em várias ocasiões fora da sala de aula. No segundo caso, que é o nosso contexto de ensino e aprendizagem, é importante criar o máximo de oportunidades para que o aluno possa dialogar com a cultura do país cuja língua está aprendendo, e, já que as situações comunicativas reais são raras, cabe ao professor criá-las na sala de aula. Cumpre também ao professor, por meio da escolha do material didático, criar o interesse comunicativo e expor o aluno à comunicação intercultural.

Verbo esserci

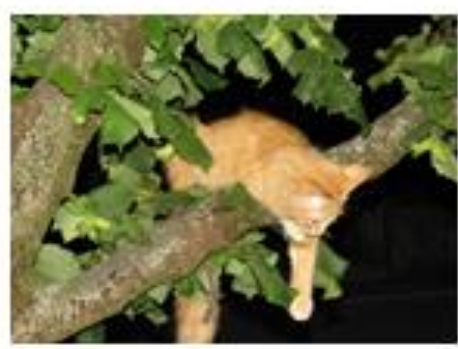

(2).

«Há um gato em cima da árvore» "Tem um gato em cima da árvores.

1. C'è un gatto sull'albero.
Ao longo de nossa experiência em ensino e aprendizagem do italiano para brasileiros, observamos que, ao anteciparmos algumas dificuldades linguísticas - e sobretudo culturais - específicas dos brasileiros, criamos uma motivação maior e preparamos o nosso aluno a enfrentar o inevitável choque cultural.

Professores e alunos brasileiros conhecem bem as dificuldades específicas do processo de ensino e aprendizagem do italiano para brasileiros; no entanto, nem sempre essas dificuldades são sistematizadas e estudadas de modo a compor, como resultado final, um material didático específico que contemple essas dificuldades, principalmente nos níveis iniciais.

A partir dessas reflexões, foram estabelecidas algumas perguntas que nortearam a pesquisa: Quais aspectos culturais são contemplados nos materiais didáticos para o ensino do italiano para estrangeiros? Os elementos apresentados são relativos à alta cultura, como cinema, literatura, teatro, ou se referem também aos elementos culturais encontrados no dia a dia? As informações culturais seriam apenas elementos curiosos, divertidos, anedotas sobre a cultura da língua estudada? As informações culturais são relevantes aos alunos brasileiros que estudam italiano?

As respostas dadas a essas perguntas nos levaram a outra pergunta: quais elementos culturais

Figura 1 - Imagem comparativa entre o português brasileiro e o italiano. 
relevantes ao aluno brasileiro não são contemplados nos materiais didáticos disponíveis para o ensino e aprendizagem do italiano?

Em nossa tese de livre-docência (BACCIN, 2012), base da fundamentação teórica deste artigo, estudamos os aspectos da comunicação intercultural entre brasileiros italianos, e muitos dos resultados teóricos dessa pesquisa foram empregados na elaboração do material didático Dire, Fare, Partire! (BACGIN et al., 2016), criando uma importante sinergia entre resultados da pesquisa e o material didático disponibilizado gratuitamente para o público em geral.

\section{Fundamentação Teórica: a Cultura e o Ensi- no da Língua Estrangeira}

Cultura é uma palavra polissêmica e, para esta pesquisa, foram selecionados os aspectos relativos à "cultura cotidiana", definida como "tudo o que distingue o 'modo de vida' de um povo, comunidade, nação ou grupo social" (HALL, 1997, p. 2).

Nesta pesquisa consideramos que cultura é um sistema adquirido e compartilhado de crenças $^{1} \mathrm{e}$ valores $^{2}$ que determinam hábitos ${ }^{3}$, regras $^{4}$, conhecimentos e tudo o que distingue o modo de vida de um grupo social. Cultura é, também, a manifestação dessas crenças, valores, hábitos, regras e conhecimentos em expressões artísticas que podem compor a "alta cultura" e a "cultura popular". E por fim, cultura é o sistema comunicativo compartilhado entre os integrantes de determinado grupo social. A cultura é aprendida, adquirida e compartilhada sempre dentro de um grupo, que começa no microgrupo que pode ser o núcleo familiar (primeira socialização) e se amplia em outros grupos (segunda socialização), até o macrogrupo que inclui toda a humanidade. Assim, entre dois países SEMPRE haverá inegáveis diversidades culturais, já que a diversidade é uma das características inerentes aos seres (BACCIN, 2012, p. 27, grifos da autora).

A "alta cultura" (ópera, pintura, escultura, museus, história) e a "cultura popular" (música, futebol, gastronomia), bem como alguns aspectos da cultura cotidiana, são abordados nos livros didáticos. Em seções dedicadas aos aspectos culturais, encontram-se, por exemplo, textos sobre os diferentes tipos de café existentes; informações de que apenas turistas tomam cappuccino à tarde ou à noite; de que não se pode subir nos ônibus sem o bilhete que é vendido nas tabacarias, ou, ainda, de que o bilhete de trem precisa ser convalidado antes do embarque; de como são as refeições dos italianos e que estas compreendem um primo e um secondo piatto (BACCIN, 2012, p. 44).

Muitos manuais para o ensino do italiano denominam-se corso di lingua e civiltà italiana, e alguns títulos que se dedicam exclusivamente à cultura são divulgados pelas editoras por meio das seguintes palavras-chave: arte, cinema, costume e società, gastronomia, geografia, letteratura, made in Italy, media, musica, nuove esigenze contemporanee, sport, storia, teatro, tradizione.

Portanto, assim como ocorre para os aspectos linguísticos, o aluno de italiano tem à sua disposição materiais elaborados pelas grandes editoras que trazem textos e exercícios sobre elementos culturais. No entanto, nem sempre esses elementos são significativos para o aluno brasileiro, que se beneficiaria de um diálogo com os aspectos contrastivos entre a cultura italiana e a brasileira.

Toda comunicação é intercultural porque coloca em contato pessoas que, de alguma forma, em grau maior ou menor, possuem hábitos, crenças, valores e regras diferentes. A percepção de que toda comunicação é intercultural contribui para a compreensão de que o outro vive em culturas (e coculturas) diferentes das nossas, e de que as soluções encontradas para determinadas situações podem diferir da solução que nós, em nossos grupos culturais, consideramos a melhor, a mais adequada, a mais correta ou a mais inteligente.

A competência comunicativa intercultural é a capacidade de compreender e interagir de maneira efetiva com pessoas de diferentes origens culturais, de modo a estabelecer um diálogo entre as culturas, prevenir ruídos na comunicação e preconceitos, bem como minimizar os efeitos do 
inevitável choque cultural. $\mathrm{O}$ aluno que é levado a refletir sobre a sua cultura em diálogo com outra cultura poderá compreender que as duas realidades são apenas diferentes, nem superiores, nem inferiores uma à outra, tornando-se um comunicador intercultural competente, não apenas quando estiver em um país estrangeiro, mas sobretudo ao mediar visitas de estrangeiros ao Brasil.

Dire, Fare, Partire! procura trazer alguns desses aspectos para o aluno brasileiro, como, por exemplo, as diferenças entre a casa brasileira e a casa italiana; os modos como as pessoas se cumprimentam, o papel de beijos, abraços e do toque entre as pessoas em um primeiro contato; como a cozinha italiana foi adaptada aos costumes alimentares dos brasileiros; a ironia e a autoironia italianas em contraste com a sensibilidade brasileira à crítica, entre outros aspectos.

\section{Metodologia: o Passo a Passo da Elabora- ção do Material}

Primeiramente foi feito o levantamento das dificuldades específicas do aluno brasileiro no processo de aprendizagem do italiano como língua estrangeira, por meio da análise de produções escritas e orais e mediante questionários.

Realizamos também um levantamento com professores de italiano nos cursos livres sobre os aspectos que eles consideravam mais difíceis para o aluno brasileiro.

Dire, Fare, Partire! foi elaborado especificamente para os alunos dos cursos de graduação em língua e literatura italiana da FFLCH-USP, ou seja, para os alunos que querem atuar como profissionais da língua italiana, sobretudo professores e tradutores.

Estudamos o curriculum e o programa dos cursos de graduação da USP, nos quais atuamos desde 1998, e, para cada tópico do programa, desenvolvemos um material que compreende videoaulas, apostilas, exercícios, sugestões de pesquisa autônoma, entre outros recursos.

Por fim, refletimos sobre os resultados obtidos na elaboração de nossa tese de livre-docência e traduzimos esses resultados em atividades para o aluno brasileiro. Para a tese, foram selecionados como temas o campo semântico da habitação e o da alimentação, analisados por meio de três instrumentos (depoimentos, questionários abertos e questionários eletrônicos) elaborados consecutivamente, e que constituem um conjunto de 576 documentos.

Convidamos todos e todas a conhecerem um pouco dos resultados obtidos clicando no clipe de divulgação disponibilizado no portal $e$-Aulas e no portal IPTV da USP ${ }^{5}$; a visitarem o ambiente Moodle de apoio, com exercícios e apostilas; ${ }^{6}$ e a acessarem o tutorial disponível no portal YouTube que apresenta todos os recursos do nosso material ${ }^{7}$.

\section{Estrutura, Recursos e Empregos nos Cursos de Graduação em Italiano da USP}

O conjunto completo de materiais compreende três temporadas, ou três módulos de dezesseis aulas cada um (total de 48 aulas):

Dire, Fare, Partire! abrange o material relativo à disciplina Língua Italiana I e tem sido utilizado desde 2015 como material didático para o curso FLM1150. Observou-se que o material não apenas responde às demandas dos nossos estudantes, mas gera, também, pesquisas em nível de pós-graduação cujos resultados ajudarão a elaborar as fases seguintes.

Dire, Fare, Arrivare! corresponde aos cursos de Língua Italiana II e III.

Dire, Fare, Ritornare!, futuramente, cobrirá o conteúdo relativo à disciplina Língua Italiana IV.

Cada aula é dividida em duas partes ${ }^{8}$. Na primeira parte, há uma série de ficção que aborda as dificuldades linguísticas e culturais típicas de um aluno brasileiro que estuda italiano no Brasil. Entre as cenas do episódio, o professor apresenta, de maneira didática, as dificuldades enfrentadas pelos personagens e apresenta elementos linguísticos e culturais relativos a cada módulo. Cada videoaula é dividida em três partes:

Abertura: no estúdio, o tópico a ser tratado na aula é apresentado, com o auxílio de cartelas e ilustrações.

Cena Ficcional: encenação de situações do cotidiano a partir de um núcleo ficcional que 
compreende três pequenas cenas que exemplificam o conteúdo e as dificuldades de um brasileiro ao se comunicar em italiano.

REFORÇO: no estúdio, a professora continua a explicação e aponta soluções para os problemas linguísticos e culturais encontrados pelos personagens.

$\mathrm{Na}$ segunda parte, há uma entrevista sobre aspectos linguísticos ou culturais. Na primeira temporada, recebemos os professores da graduação e da pós-graduação de italiano da FFLCH; foram realizadas duas entrevistas via Skype com professoras das Universidades de Veneza e Pádua; recebemos o adido cultural do Consulado Geral da Itália em São Paulo; dois doutorandos do nosso Programa; uma aluna da graduação, e, via Skype, uma aluna egressa do curso de graduação que mora na Itália nos falou sobre diferenças entre Brasil e Itália relativas à moda.

As unidades de aprendizagem consistem de uma videoaula, um capítulo de apostila e uma unidade de exercícios multimídia.

A apostila é disponibilizada em PDF e em formato eletrônico com feedback automático e áudio, de modo que o aluno pode fazer os exercícios on-line e ter as respostas imediatas ou imprimir o material para o estudo autônomo. O recurso de áudio permite que o aluno que realiza seu estudo de maneira autônoma possa verificar se está pronunciando corretamente as palavras.

\section{Considerações Finais}

Dire, Fare! é um conjunto de materiais que compreende elementos que oferecem dificuldades ao aluno brasileiro e que, geralmente, não são tratados nos manuais didáticos tradicionais elaborados para alunos de italiano na Itália (L2) e para aqueles que estudam o italiano em seus países (BACGIN, ORTALE, MAGGIO, 2016). Como atuamos em contexto de língua estrangeira, ou seja, no qual o aluno aprende o italiano fora da Itália, é importante criar o máximo de oportunidades para que ele possa dialogar com a cultura do país cuja língua está aprendendo, já que as situações comunicativas reais são raras.

Os professores e alunos brasileiros conhecem bem as dificuldades específicas desse processo; no entanto, nem sempre encontram material didático específico para essas dificuldades, sobretudo, nos níveis iniciais. Graças à parceria com o Departamento de Mídias Digitais da USP, o conteúdo linguístico e cultural foi adaptado de modo a receber um tratamento artístico voltado a obter a comunicação mais eficaz com o aluno (BACGIN, ORTALE, MAGGIO, 2016).

Para a segunda temporada, realizamos videoaulas e capítulos da ficção ambientados na Itália, de modo a auxiliar o aluno brasileiro a se aproximar dos problemas reais de comunicação intercultural de um brasileiro na Itália, não apenas de maneira teórica, mas com vistas a compreender o mecanismo de conhecer a si mesmo para conhecer o outro.

Acreditamos que a presente proposta atinge plenamente os objetivos da universidade pública, uma vez que disponibiliza, gratuitamente, para o público em geral, os resultados gerados no âmbito da pesquisa e do ensino gerado na Universidade.

\section{Notas}

1 Crença como convicção profunda que carrega uma componente de valor (cf. ROKEACH, 1973).

2 Valor é uma palavra polissêmica que assume, de acordo com o contexto e o campo de estudo, uma definição específica. Neste contexto, significa a concepção de um indivíduo ou de um grupo de indivíduos sobre o que é idealmente desejável. Uma escala cujas extremidades contêm o nível máximo de desejabilidade, de um lado, e, no outro extremo, o nível máximo de rejeição. Exemplos: o bem e o mal; limpo e sujo; seguro e perigoso; decente e indecente; belo e feio; racional e irracional; moral e imoral. Os valores influenciam a maneira de agir, os significados e os fins das ações. $\mathrm{O}$ mesmo valor ou conjunto de valores são sempre ativados em situações diversas e, apesar de relacionados e de formarem sistemas (ou hierarquias) de valores, podem entrar em conflito entre si (cf. HOFSTEDE, 2001, pp. 1-9).

3 Hábito como maneira permanente ou frequente de comportamento.

4 Regra como norma que rege o modo de pensar e agir em determinados casos.

5 Disponível em: >http://www.eaulas.usp.br/portal/ video.action?idItem $=5541>$. 
6 Disponível em: \http://cursosextensao.usp.br/coursel view.php?id $=131>$.

7 Disponível em: <https://www.youtube.com/ watch? $\mathrm{v}=\mathrm{jgA} 1 \mathrm{SOPzyAs}>$.

8 Cf. BACGIN, ORTALE, MAGGIO, 2016, para a descrição completa da estrutura do curso.

\section{Referências Bibliográficas}

ABBOTT, Charles. "Brazil". In: Culture Smart. The Essential Guide to Customs and Culture. London: Kuperard, 2008.

BACGIN, Paola Giustina. "Reflexões sobre Elaboração de Material e Atividades Lúdicas". In: GULLO, Annita; SOBRAL, Carlos; SANTOS, Maria Lizete dos (orgs.). L'Italiano Oltre $i$ Confini. Rio de Janeiro: Letras/UFRJ, 2011.

o Dicionário Bilíngue para Aprendizes: uma Ponte entre Duas Culturas. Tese de livre-docência. Faculdade de Filosofia, Letras e Ciências Humanas da Universidade de São Paulo, 2012.

BACGIN, Paola; MAGGIO, Giliola; ORTALE, Fernanda. "Dire, Fare, Partire! Um Material Didático On-Line Específico para Brasileiros". In: ORTALE, F. \& FERRONI, R. Luz, Câmera e Ação: o Professor Autor na Sala de Aula de Linguas. São Paulo: Humanitas, 2016.

BELISÁRIO, A. "O Material Didático na Educação à Distância e a Constituição de Propostas Interativas". In: SILVA, M. (org.). Educaşão Online: Teorias, Práticas, Legislação e Formação Corporativa. São Paulo: Loyola, 2003, pp. 135-146.

BRANCO, Sandra \& WILLIAMS, Rob. "Brazil". In: Culture Smart. The Essential Guide to Customs and Culture. London: Kuperard, 2011.

FLOWER, Raymond \& FALASSI, Alessandro. Culture Shock! Italy: A Survival Guide to Customs and Etiquette. Tarrytown, NY: Marshall Cavendish Editions, 2008.
HALL, Edward T. Beyond Culture. New York: Anchor Books, 1976.

HALL, Stuart. "The Work of Representation". In: HALL, Stuart (org.). Representation: Cultural Representations and Signifying Practices. Londres: Thousands Oaks, 1997

HOFSTEDE, Geert. Culture's Consequences. London: Sage, 2001.

NOVINGER, Tracy. Communicating with Brazilians. When "Yes" Means "No". Austin: University of Texas Press, 2003.

PAVAN, Elisabetta. "Cultura e Civiltà nella Classe di Lingua". In: SERRAGIOTTO, G. (org.). Le Limgue Straniere nella Scuola. Torino: Utet Libreria, 2004, pp. 56-69.

"La Dimensione Interculturale nella Comunicazione: una Questione di Consapevolezza". In: MEZZADRI, M. (org.). Le Lingue dell'Educazione in un Mondo senza Frontiere. Perugia: Guerra Edizioni, 2010.

PICHIASSI, M. Apprendere l'Italiano L2 nell'Era Digitale. Le Nuove Tecnologia nell'Insegnamento e Apprendimento dell'Italiano per Stranieri. Perugia: Guerra Edizioni, 2007.

POELZL, Volker. Culture Shock! A Survival Guide to Customs and Etiquette. Brazil. London: Marshall Cavendish Editions, 2002.

ROKEACH, Milton. The Nature of Human Values. New York: The Free Press, 1973.

SCOLLON, Ron; SCOLLON, Suzanne Wong; JONES, Rodney H. Intercultural Communication: a Discourse Approach. West-Sussex: Wiley-Blackwell, 2012.

TROMPENAARS, Alfons \& HAMPDEN-TURNER, Charles. Riding the Waves of Culture. New York: McGraw-Hill Publishing, 1997.

VIEIRA, D. A. A Didatização de Materiais Autênticos para o Ensino do Italiano Lingua Estrangeira. São Paulo: Humanitas, 2013.

Publicado em 11/11/2016. 